\title{
LOSS OF RETINOID RECEPTORS RAR-A AND RXR-A DURING MONOCROTALIN/LIPOPOLYSACCHARIDE-INDUCED RENAL TOXICITY IS TISSUE FACTOR DEPENDENT
}

\author{
Mohamed Sadek Abdel-Bakky \\ Faculty of Pharmacy, Al-Azhar University, Nasr City, Cairo, Egypt
}

\begin{abstract}
:
Retinoic acid receptors (RARs) are ligand-controlled transcription factors that function as heterodimers with retinoid X receptors (RXRs) to regulate cell growth, differentiation, survival and death. Due to their regulatory potential, these nuclear receptors (NRs) are major drug targets for a variety of pathologies, including cancer and metabolic diseases. We reported earlier the involvement of tissue factor (TF) in the release of retinoid receptors RAR- $\alpha$ and RXR- $\alpha$ as accumulated lipid droplet during monocrotaline/lipopolysaccharide (MCT/LPS)-liver injury in mice. In the kidney, little is known about the localization and the functional significance of RXR- $\alpha$ and RAR- $\alpha$. In this study, we were able to find RXR- $\alpha$ receptor in distal, proximal tubules as well as glomeruli of mice kidney. In addition, RAR- $\alpha$ expression is restricted to the glomeruli and endothelial cells of the blood vessels. Furthermore, following MCT/LPS co-treatment, we found the translocation of RXR- $\alpha$ from basolateral into the apical site in the distal tubules and collecting duct along with downregulation of glomerular RAR- $\alpha$. This study reports the involvement of $\mathrm{TF}$ in the tubular translocation of retinoid receptor RXR- $\alpha$ and the glomerular downregulation of RAR- $\alpha$ during MCT/LPS-renal injury. The fact that TF antisense oligonucleotides (TF-AS ODN) treatment not only down-regulated TF but also obliterated the tubular translocation of RXR- $\alpha$ and glomerular RAR- $\alpha$ downregulation points towards TF being an important regulatory molecule for renal RAR- $\alpha$ and RXR- $\alpha$.
\end{abstract}

Keywords: Tissue Factor, retinoic acid receptor alpha, retinoid X receptor alpha, tissue factor antisense oligodeoxynucleotides

\begin{abstract}
Abbreviations: TF, Tissue factor; MCT, monocrotaline; LPS, lipopolysaccharide; RAR- $\alpha$, retinoic acid receptor alpha; RXR- $\alpha$, retinoid X receptor alpha; TF-AS ODN, Tissue factor antisense oligodeoxynucleotide; RA, retinoic acid; RARE, RA response element; RXRE, retinoid X response element.
\end{abstract}

\section{INTRODUCTION}

Retinoids are essential in maintaining normal cell function such as proliferation, differentiation, healthy immune system, normal male and female reproduction, and vision (Goodman, 1984). Retinoic acid (RA), an active metabolite of vitamin A is a requirement for vision, development and reproduction. During embryonic period it affects the normal development of different organs and tissues (Quadro et al., 2004). RA mediates these activities by binding to two families of nuclear receptors, the retinoic acid receptors (RARs) and the retinoid $\mathrm{X}$ receptors (RXRs), each of these families comprises three isotypes $(\alpha, \beta$ and $\gamma$ ) which affect transcription of a number of genes during vertebrate development (Snyder et al., 2005). In kidney both RARs and RXRs are cell specific in expression; these are therefore, practically responsible for activation of both receptors by their respective agonists (Wagner, 2001). 
RARs function as a RAR/RXR heterodimer that is activated by RARa agonists. RXR agonists synergize with RAR ligands to activate the heterodimer. In contrast, RXRs function as either a homodimer or a heterodimer with a variety of partners including RAR, peroxisome-proliferator activated receptor (PPAR), thyroid hormone receptor (THR), vitamin D receptor (VDR), and orphan nuclear receptors (Abdel-Bakky et al., 2011).

RAR- $\alpha$ is expressed during mouse nephrogenesis in the stromal cell layer (Dolle $\boldsymbol{e t}$ al., 1990; Mendelsohn et al., 1999). In addition, RXR- $\alpha$ also expressed during nephrogenesis, but unlike RARs, RXRs are expressed in the epithelial components of the kidney, specially the proximal and distal tubules, with no expression in the glomeruli ( $\alpha$ and $\beta$ ) and the inner medullary collecting ducts ( $\beta$ only); (Sugawara et al., 1997; Yang et al., 1999).

In our recent work, we found the retinoid receptors, RAR- $\alpha$ and RXR- $\alpha$ in the released lipid droplets from hepatic stellate cells (HSCs) of our new Monocrotalin/Lipopolysaccharid (MCT/LPS) idiosyncratic liver toxicity model. In the study, we were able to prove the possibility of using both proteins as early and sensitive markers for HSCs activation. Interestingly, we found in another work that the subtoxic doses from MCT and LPS co-treatment induce renal toxicity as the common renal toxicity markers such as creatinin, blood urea nitrogen (BUN) and proteinuria were elevated.

Signaling of retinoic acid (RA) is mediated via its occupancy of retinoic acid receptors (RAR) and retinoid X receptors (RXR), with subsequent DNA binding of a RARRXR heterodimer or a RXR-RXR homodimer to Retinoic acid response element (RARE) or retinoid X response element (RXRE), respectively (Mangelsdorf and Evans, 1995). This regulates the transcription of target genes that control cellular proliferation, differentiation, and apoptosis (Ohata $\boldsymbol{e t}$ al., 1997). RAR-selective agonists are clinically used for treatment of cancers, acne, and psoriasis, whereas RXR agonists show potential for the treatment of hyperglycemia in animal models of type II diabetes (Nagpal and Chandraratna, 2000).

RARs regulate the transcription of responsive genes as heterodimers with RXRs. In contrast, RXRs play a central role in nuclear receptor signaling, by either forming homodimers or by acting as obligatory heterodimerisation partners for a variety of nuclear receptors (e.g, RARs, peroxisome proliferator activated receptors, vitamin D receptors). Cytosolic speckled RAR- $\alpha$ distribution has been observed in activated HSC in vitro (Mezaki et al., 2009) and in vivo in our recent publication (Abdel-Bakky et al., 2011).

Very few data exist about the expression of RXR- $\alpha$ and RAR- $\alpha$ in the kidney and their role in renal disease progression. In addition, the possible relation between TF and the retinoid receptors (RXR- $\alpha$ and RAR- $\alpha$ ) need to be clarified.

Tissue factor (TF) is one of the major physiological initiators of the coagulation cascade and has an important function in the morbidity and mortality associated with many disease states (Drake $\boldsymbol{e t}$ al., 1993). Earlier reports indicate activation of TF in MCT/LPSinduced liver injury in mice (Hammad $\boldsymbol{e t}$ al., 2011; Yee $\boldsymbol{e t}$ al., 2003). There is a dearth of information on the association of activation $\mathrm{TF}$ and expression of retinoid receptors in renal injury. In this study, we attempt to investigate renal RAR- $\alpha$ and RXR- $\alpha$ protein expression in normal and after MCT/LPS-induced renal injury. In addition, the association of TF activation and expression of RAR- $\alpha$ and RXR- $\alpha$ in this model will also be investigated. 


\section{MATERIALS AND METHODS}

\section{Animals and animal model}

Male ND-4 mice were obtained from Harlan Lab (Indianapolis, IN, USA) at 5 weeks of age and 21-24 g of weight upon receipt. Prior to the experiment, mice were fasted for 12 $\mathrm{h}$ and randomly assigned into seven groups. Vehicle/vehicle: saline (po) followed $4 \mathrm{~h}$ by saline (ip); MCT/vehicle: MCT (po) followed $4 \mathrm{~h}$ by saline (ip); vehicle/LPS: saline (po) followed $4 \mathrm{~h}$ by LPS (ip); MCT/LPS: MCT (po) followed $4 \mathrm{~h}$ by LPS (ip); The other three groups received ODNs (TF-SC,TF-SE, and TF-AS, $5.6 \mathrm{mg} / \mathrm{kg}$ ) in MCT/LPS-treated mice right after MCT administration and $3.5 \mathrm{~h}$ before LPS administration. Following the abovementioned treatments, food was made available ad libitum. MCT $(200 \mathrm{mg} / \mathrm{kg})$ and LPS (6 $\mathrm{mg} / \mathrm{kg}$ ) doses were selected for this study based on our previous work (Abdel-Bakky et al., 2010; Yee et al., 2003). TF ODNs $(5.6 \mathrm{mg} / \mathrm{kg})$ i.v. were selected during our preliminary work.

\section{Sample Collection}

At $24 \mathrm{~h}$ post treatments animals were euthanized by $\mathrm{CO} 2$ asphyxiation. Samples from kidney were taken and processed by standard histological techniques.

\section{Antibodies and chemicals}

Rabbit polyclonal RAR- $\alpha$ and RXR- $\alpha$ antibodies were purchased from Santa cruz biotechnology (Santa Cruz, CA, USA). Cy3 conjugated goat anti-rabbit antibody was purchased from Jackson Immunoresearch (West Grove, PA, USA). 40, 60-Diamidino-2phenylindole (DAPI), lipopolysaccharide (LPS) and monocrotaline (MCT) were purchased from Sigma-Aldrich (St. Louis, MO, USA). Rabbit polyclonal IgG for tissue factor and mouse monoclonal IgG1 for Wilms' tumor (WT1) were purchased from Santa Cruz biotechnology, inc. (Santa Cruz, CA, USA).

\section{Tissue factor oligonucleotides}

The oligonucleotides used in these studies were purchased from integrated DNA technologies (San Diego, CA, USA). The following sequences of the mouse TF antisense, sense and scrambled nucleotides were used.

Antisense TF (TF-AS), 5'CATGGGGATAGCCAT-3`; sense TF (TFSE), 5`ATGGCTATCCCCATG-3`; scrambled TF (TF-SC), 5 '-TGACGCAGAGTCGTA-3`

\section{Blood chemistry}

Blood samples $(100 \mu \mathrm{L}), 24 \mathrm{~h}$ after different treatments, obtained by venipuncture were analyzed using the VetScan ${ }^{\circledR}$ Comprehensive Diagnostic Profile reagent rotor used with the VetScan Chemistry Analyzer (Abaxis Inc., Union City, CA, USA). The blood samples were collected in heparinized micropipette and transferred into the reagent rotor and run within 30 minutes of collection. A quantitative determination of alkaline phosphatase (ALP), creatinine (CRE), globulin phosphorus (PHOS) and urea nitrogen (BUN) were obtained.

\section{Immunofluorescence analysis on renal tissue sections}

Paraffin tissue sections were deparaffinized in xylene, rehydrated through a graded ethanol series and washed in $10 \mathrm{mM}$ phosphate-buffered $150 \mathrm{mM}$ saline, $\mathrm{pH}$ 7.4. Antigen retrieval were performed by incubating the tissue sections for $20 \mathrm{~min}$ in $0.01 \mathrm{M}$ sodium citrate buffer, $\mathrm{pH} 6.0$, in a microwave oven $(500 \mathrm{~W})$. To block endogenous peroxidase, slides were incubated with absolute methanol for $30 \mathrm{~min}$. After incubation with blocking 
buffer $(0.1 \%$ Triton X-100/PBS containing $1 \%$ BSA and $10 \%$ horse serum) for $1 \mathrm{~h}$, tissue sections were incubated with the primary antibodies (diluted in 1\% BSA $10 \%$ horse serum/PBS/0.1\% Triton X-100) as required. Following washing, bound antibodies were detected by goat anti-rabbit Cy3 (Molecular Probes) or goat anti-mouse Alexa 488 (Invitrogen) secondary antibodies for $30 \mathrm{~min}$. Nuclei were stained with 40,6-diamidino-2phenylindole (DAPI, Sigma) and slides were mounted in Fluoromount G (Biozol, Southern Biotech, Birmingham, AL). Evaluation was performed by fluorescence microscopy (Carl Zeiss, CA). Fluorometric intensity of 5-8 microscopic fields were measured for each tissue section using ImageJ/NIH software.

\section{Plasma IL-6 measurement.}

Plasma was analyzed with the Quantibody ${ }^{\circledR}$ Mouse Cytokine Custom Array (Raybiotech, Norcross, GA, USA) for IL-6. Slides were incubated with the plasma samples and analyzed in accordance with the manufacturer's instructions and the results are expressed as $\mathrm{ng} / \mathrm{ml}$.

\section{Statistical analysis}

Data were analyzed by one-way ANOVA followed by Tukey's test for multiple comparisons using Graph Pad prism 5.0 software (La Jolla, CA, USA). A P-value of less than 0.05 was considered to show a significant difference among the groups.

\section{RESULTS}

\section{Renal toxicity developed in mice by (po) MCT/(ip) LPS co-treatment}

Blood levels of BUN, creatinine, ALP and phosphorus were measured before MCT/LPS and/or TF ODNs treatment. Twenty four hrs after MCT/LPS, MCT/LPS-TF-SC or MCT/LPS-TF-SE administration, the levels of BUN, creatinine and phosphorus were significantly increased. On the other hand, blood ALP level was significantly reduced compared to the vehicle treated group. Injecting the animals with TF-AS, 30 min after MCT administration and $3.5 \mathrm{~h}$ before LPS clearly prevented the deleterious effect of MCT/LPS cotreatment. The BUN/creatinine ratio was significantly increased after MCT/LPS, MCT/LPSTF-SC or MCT/LPS-TF-SE administration compared to the vehicle treated mice. Apparently, TF-AS injection prevented the elevation of BUN and creatinine. On the other hand, it prevented the reduction of blood ALP compared to MCT/LPS-TF-SE (Figure 1).

\section{TF antisense ODNs effectively block renal TF protein expression}

Tissue TF was highly accumulated in the tubules and in the glomerular cells of MCT/LPS co-treated mice compared to veh. as shown with specific TF immunofluorescence in renal tissues. On the other hand, injection of TF-AS in MCT/LPS co-treated mice showed considerably less accumulation of $\mathrm{TF}$ in the tubules and in the glomeruli compared to MCT/LPS co-treated mice (Figure 2A). No changes appeared in tissue TF in MCT/LPSTF-SC or MCT/LPS-TF-SE treated mice compared to MCT/LPS co-treatment alone.

\section{TF-AS attenuated renal inflammation and selectively decreased IL-6 production.}

In combination with modulated blood chemistry, TF-AS injection also significantly diminished blood IL-6 $(9.553 \pm 0.2085 \mathrm{ng} / \mathrm{ml})$ production induced by MCT/LPS in mice $(37.226 \pm 1.368 \mathrm{ng} / \mathrm{ml})$ but still higher than veh. $(2.177 \pm 0.2085 \mathrm{ng} / \mathrm{ml})$, figure $2 \mathrm{~B}$. 


\section{Effect of MCT/LPS with or without TF antisense ODNs on renal RXR- $\alpha$}

Normal mice kidneys showed a constitutive expression of RXR- $\alpha$ in the glomerular cells as well as in the distal tubules and collecting ducts (Figure 3). In contrast, both the proximal tubules and the loop of Henle had negative RXR- $\alpha$ expression. Interestingly, a translocation of RXR- $\alpha$ from basolateral (outer) into apical (luminal) in MCT/LPS, MCT/LPS-TF-SC and MCT/LPS-TF-SE treated mice was observed relative to the vehicle treated group. In addition, a significant reduction in glomerular RXR- $\alpha$ protein expression in MCT/LPS, MCT/LPS-TF-SC and MCT/LPS-TF-SE treated mice was observed compared to the vehicle treated group. In contrast, TF-AS injection prevented RXR- $\alpha$ translocation in the tubules. Furthermore, TF-AS treatment in combination with MCT/LPS obliterated the glomerular downregulation of RXR- $\alpha$ compared to MCT/LPS, MCT/LPS-TF-SC and MCT/LPS-TF-SE (Figure 3).

\section{TF-AS effect on RAR- $\alpha$ changes caused by MCT/LPS co-treatment}

The results show, for the first time, RAR- $\alpha$ expression is restricted to the glomerular cells (glomerular basement membrane and/or podocytes) with neglected expression in the tubules of cortical area. After co-administration of MCT/LPS, MCT/LPS-TF-SC and MCT/LPS-TF-SE, down regulation of glomerular RAR- $\alpha$ protein expression and strong expression of the protein in the interstitial epithelial cells (Figure 4).

\section{DISCUSSION}

Tissue factor (TF) is expressed on the surface of monocytes and endothelial cells in a number of pathological conditions. Increased monocytic TF levels is detected in unstable angina pectoris, endotoxemia with or without disseminated intravenous coagulation (DIC), some malignancies and certain immunological diseases (Edgington et al., 1992; Rothberger et al., 1984). Renal TF expression is restricted to the glomerular podocytes, bowman epithelium and the tubular loop of Henle (Belting et al., 2004; Bromberg et al., 1999; Mach et al., 1997). The current study showed that co-treatment with subtoxic doses of oral MCT and ip LPS led to induction of renal injury, whereas the individual treatments did not. The toxicity was confirmed by elevation of the renal toxicity markers including blood BUN, creatinine, BUN/creatinine ratio and ALP. Since oliguria was a characteristic feature in the animals after the co-treatment with MCT/LPS, it was difficult to collect urine for urinalysis.

The study documented up-regulation of the tissue TF level at $24 \mathrm{~h}$ after MCT/LPS co-treatment. These data are similar to those shown earlier (Frank et al., 2005) where upregulation of TF mRNA was reported in renal ischemia reperfusion (I/R) murine model. After prolonged renal ischemia and contralateral nephrectomy in a rat model, TF was upregulated in the kidney with increased TF staining in glomeruli, blood vessels, and stimulated monocytes (Ushigome $\boldsymbol{e t}$ al., 2002). The same study, using a less severe model, has subsequently shown protection from tubular necrosis by the use of TF antisense oligonucleotides (Matsuyama et al., 2003). The mechanism underlying TF-mediated injury was not explored, although it was postulated that necrosis was caused by microcirculatory incompetence and microthrombus formation.

An important therapeutic concept in support of anti-TF strategies to target many toxicity types involves the known cross-talk between coagulation and inflammation through TF-VIIa complex, factor Xa, thrombin, and fibrin (Cirino et al., 1997; Cunningham et al., 1999; Johnson et al., 1998; Shin et al., 1999). TF-VIIa has intracellular calcium-dependent 
signaling functions (Rottingen $\boldsymbol{e t}$ al., 1995) and perhaps other intracellular signaling effects via phosphorylation of mitogen activated protein kinases (Poulsen $\boldsymbol{e t}$ al., 1998; Sorensen $\boldsymbol{e t}$ $\boldsymbol{a l}$. , 1999). These effects enhance cytokine production (Camerer et al., 2000), inflammation, and may alter endothelial permeability. Factor $\mathrm{Xa}$ and thrombin also have potent proinflammatory effects, mediated in part by nuclear factor- $\beta$ activation (Shapiro et al., 1996; Shin et al., 1999; Stankova et al., 1995). In the present study, the glomerular capillary lumens, glomerular podocytes, distal tubular epithelial cells in the cortical region and the necrotic tubules in the medullary area were showed extensive deposition of TF in MCT/LPS co-treated mice kidney.

The susceptibility to urinary tract infections increases in vitamin A deficiency and decreases with supplementation of vitamin A (Kavukcu et al., 2001). Similarly, patients with a low serum vitamin A level have an increased susceptibility to chronic pyelonephritisinduced renal scarring, and the severity of renal scarring decreases with vitamin A supplementation in experimentally induced pyelonephritis in rats (Kavukcu et al., 2001). In the 5/6 nephrectomy model, characterized by focal segmental glomerulosclerosis, tubular degeneration, and interstitial fibrosis, low-dose vitamin A supplementation tends to reduce glomerular and interstitial injury, although high-dose vitamin A exacerbates injury in both compartments (Kavukcu et al., 2001).

No report exists on the expression of vitamin A receptors, RAR- $\alpha$ and /or RXR$\alpha$ during renal injury. In the current work, we found constitutive expression of RAR- $\alpha$ restricted to the endothelial cells of the blood vessels as well as in glomeruli (could be podocytes). It is well accepted that the number of podocytes is reduced in several animal models including diabetic nephropathy (Susztak et al., 2006). In multiple experimental models of kidney diseases including puromycin aminonucleoside (PAN)-induced nephropathy, mesangioproliferative glomerulonephritis, lupus nephritis, and diabetic nephropathy, all-trans retinoic acid, the vitamin A active metabolite, has been shown to be renoprotective. All trans retinoic acid (tRA) alleviates PAN-induced proteinuria and the effacement of podocyte foot processes. In addition, administration of all-trans retinoic acid prior to PAN treatment protects animals from proteinuria and podocyte injury (MorenoManzano et al., 2003). The down-regulation of glomerular RAR- $\alpha$ after MCT/LPS cotreatment could be the results of podocyte effacement.

In the current study, a constitutive expression of RAR- $\alpha$ in the medullary tubules particularly distal and collecting duct. When MCT/LPS co-treatment was given, RAR- $\alpha$ tubular expression was strongly up-regulated compared to vehicle treated mice. Mendelsohn C, (1999) and his group reported that, mice injected with RA showed increase in the thickness of renal medulla with closely packed tubules due to increased tubulogenesis induced by RA (Mendelsohn et al., 1999). Other study mentioned that, tRA significantly stimulates renal tubular epithelial cell proliferation with (Argiles et al., 1989) or without (Anderson et al., 1998) significant hypertrophy, and therefore might be involved in the functional compensation, hypertrophy, and repair of renal tubules. Up-regulation of RAR$\alpha$ could be due to the increased tubular epithelial cell proliferation and therefore increased RAR- $\alpha$ expression, the effect which considered as compensatory mechanism for tubular necrosis.

Interleukin (IL)-6 is a cytokine that is primarily involved in the regulation of immune and inflammatory responses. In renal ischemia/reperfusion (I/R) injury, a significant and sustained increase in the expression of the IL-6 gene was reported (Takada et al., 1997). IL6 can induce a prothrombotic state by increasing expression of fibrinogen, tissue factor, factor VIII and von Willebrand factor, as well as by activating endothelial cells and 
increasing platelet production (Kerr et al., 2001). In the intestine, increased expression of IL-6 contributes to gut I/R injury (Cuzzocrea et al., 1999). In our study, the increased IL-6 level caused by MCT/LPS co-treatment, was inhibited by injection of tissue factor antisense oligonucleotides (TF-AS ODNs); whereas injection of tissue factor scrambled (TF-SC) or tissue factor sense (TF-SE) did not prevent its increase. It appears that elevation of IL-6 in renal injury induced by MCT/LPS is a TF dependent process.

In the current work, we obviously showed increased expression of tissue factor (TF) in renal cortical distal tubules and collecting ducts after MCT/LPS co-treatment compared to vehicle treated mice. The findings in this study suggests that, TF-AS prevented TF expression caused by MCT/LPS, which led to prevention of coagulation process and thus prevented pathological changes in the renal tissue. Furthermore, co-treatment with MCT/LPS showed translocation of RXR- $\alpha$ from basolateral into the apical site of the cortical tubule compared to its distributed expression in vehicle treated mice. As of yet, few data exist about the possible interdependence between the retinoid receptors (RXR- $\alpha$ or RAR- $\alpha$ ) and TF. It has been shown that RA prevents TNF-alpha induced TF activity of lysed cultured umbilical vein endothelial cells (Ishii et al., 1992). Tenno et al, 2000 have shown down-regulation of TF in myeloid leukemic cells by retinoids (Tenno et al., 2000). In the same study, the authors concluded that, retinoid-induced suppression of TF appeared to be dependent on the activation of both members of RAR- $\alpha$ and RXR- $\alpha$ transcriptional complex. It is not known if RAR- $\alpha$ and RXR- $\alpha$ expression is dependent on TF up-regulation in vivo. Blocking of $\mathrm{TF}$ by $\mathrm{TF}-\mathrm{AS}$ oligonucleotides in the current study prevented the glomerular down-regulation RAR- $\alpha$ and the increased tubular epithelial cell proliferation expressing RAR- $\alpha$ as well as the apical translocation of RXR- $\alpha$ in the renal cortical tubules after MCT/LPS co-treatment. This confirms earlier views of interdependence of TF and both RXR and RAR expression (Tenno et al., 2000).

In conclusion, this is the first report showing in vivo expression of RXR- $\alpha$ and RAR$\alpha$ in normal and renal injury resulting from MCT/LPS co-treatment. Furthermore, apical translocation of RXR- $\alpha$ and glomerular down-regulation and renal epithelial extensive expression of RAR- $\alpha$ as consequence of MCT/LPS co-treatment could be prevented by TFAS ODNs injection. Our results could provide new avenue of using RXR- $\alpha$ and/or RAR- $\alpha$ as urinary biomarkers for renal injury in general and toxicity from MCT/LPS in particular. Compared to RAR- $\alpha$, RXR- $\alpha$ appears to be promising marker based on its apical translocation in the tubules. Further researches need to be performed to track these proteins in the urine of different etiological kidney diseases. In summary, RXR- $\alpha$, RAR- $\alpha$ and TF may emerge as important regulatory molecules and play important role in renal injury. Targeting TF could open new avenues for treatment of renal injury.

\section{Funding}

This work was supported in part by the United States Department of Agriculture, Agricultural Research Service, Specific Cooperative agreement [58-6408-2-0009] and US Food and Drug Administration [5U01FD002071-09 and 1U01FD003871-011]. 
A

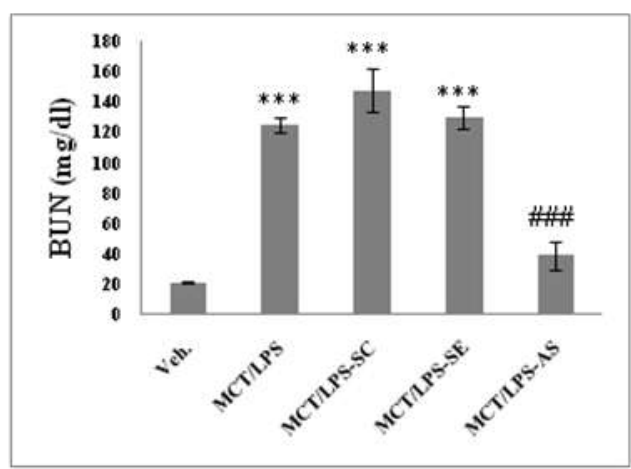

B

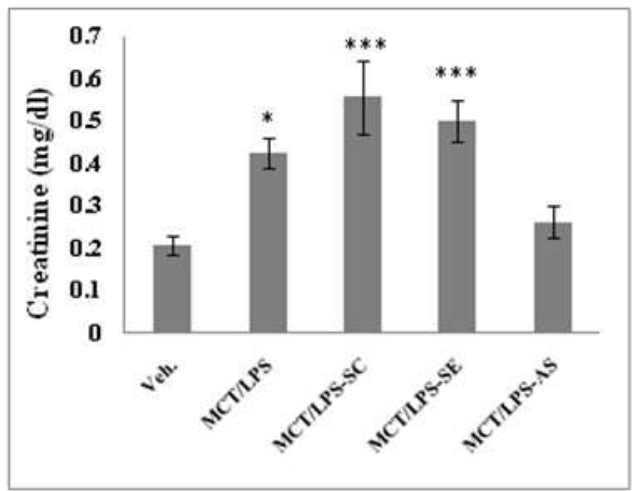

C

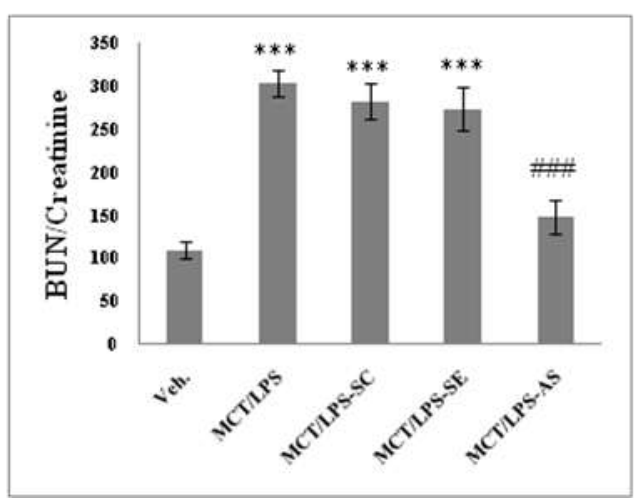

D

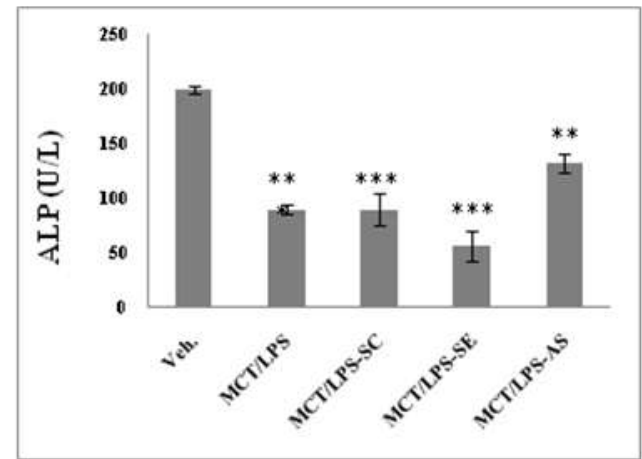

$\mathbf{E}$

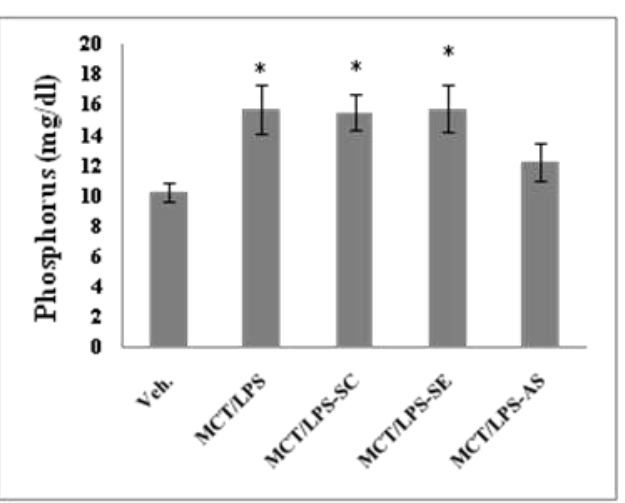

$\mathbf{F}$

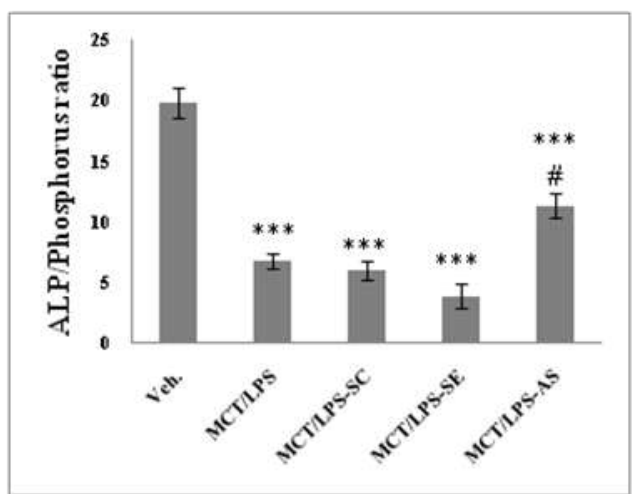

Figure 1: Effect of combined treatments of MCT and LPS on blood chemistry;

Mice ( $\mathrm{n}=8-20)$ were treated with veh. or treated with MCT $(200 \mathrm{mg} / \mathrm{kg})$ and LPS (6 $\mathrm{mg} / \mathrm{kg}$ ) with or without i.v. injection of $5.6 \mathrm{mg} / \mathrm{kg}$ of TF-SC, TF-SE or TF-AS. A quantitative determination of urea nitrogen (BUN, A), creatinine (CRE, B), ), ratio of BUN/creatinine (C), alkaline phosphatase (ALP, D), globulin phosphorus (PHOS, E) and the ratio of $\mathrm{ALP} /$ phosphorus $(\mathrm{F})$ was performed.

Data are shown as mean \pm SE and analyzed with one way analysis of variance followed by Tukey's for multiple comparisons. ${ }^{*} \mathrm{P}<0.05 ;{ }^{* *} \mathrm{P}<0.01 ;{ }^{* * *} \mathrm{P}<0.001$; significantly different compared to veh. treated animals. ${ }^{\#} \mathrm{P}<0.05$; ${ }^{\# \# \#} \mathrm{P}<0.001$; significantly different compared to MCT/LPS treated animals. 


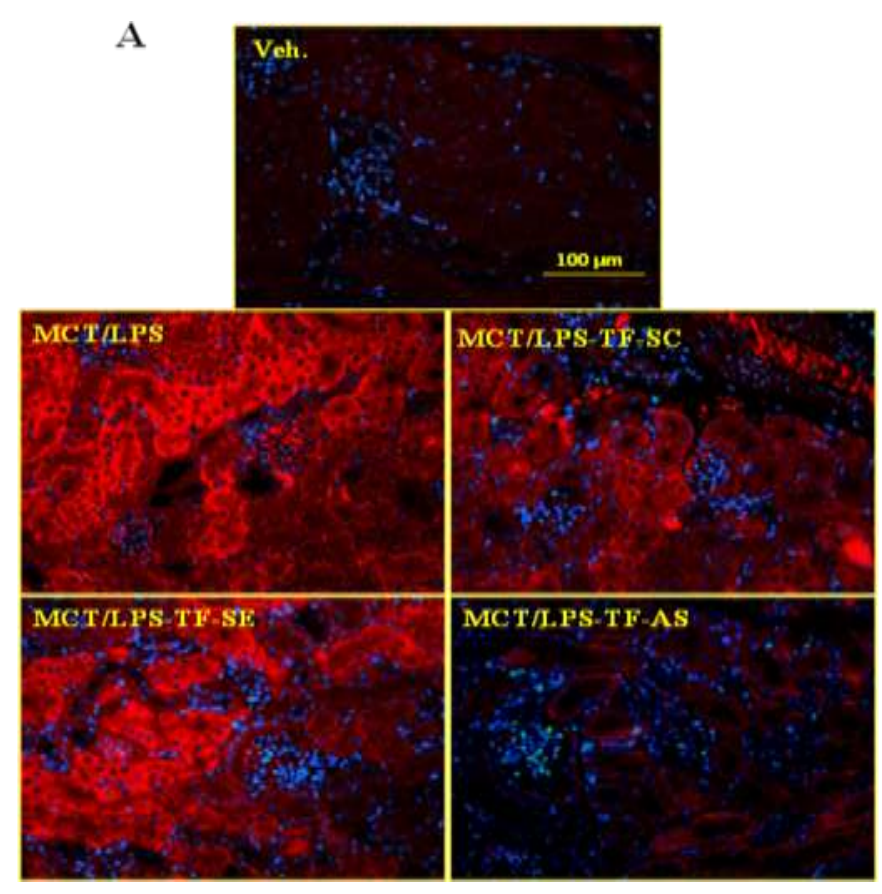

B

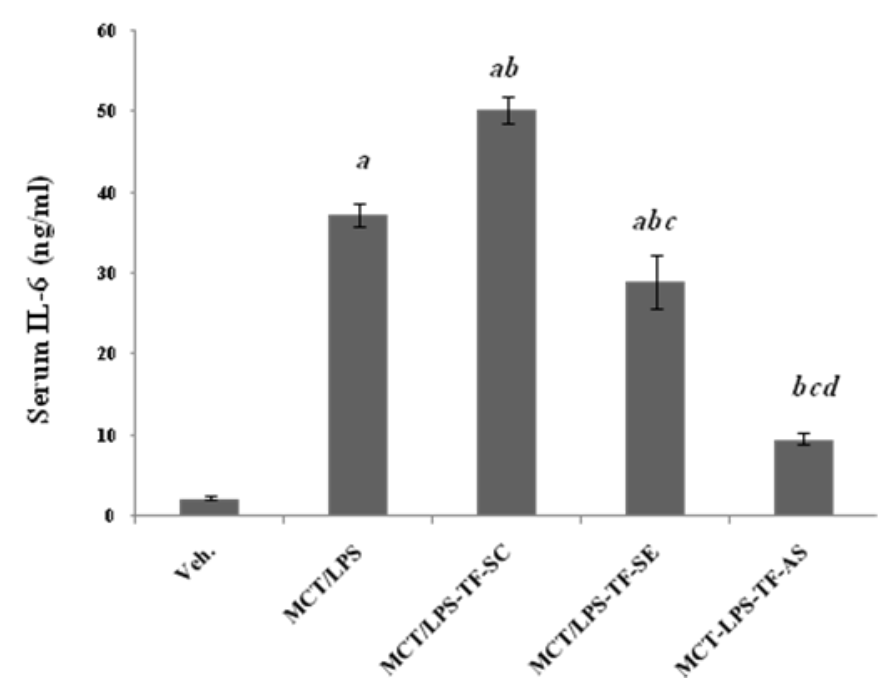

Figure 2: (A) Immunofluorescence staining of TF in kidney sections of animals co-treated with MCT/LPS, showing increased deposition in the tubular and glomerular cells compared to veh.-treated mice $24 \mathrm{~h}$ after co-treatment. Similar deposition pattern of renal TF is seen in MCT/LPS-TF-SC and MCT/LPSTFSE compared to MCT/LPS co-treated mice. Slight deposition of TF is seen in the renal tubules or glomeruli in MCT/LPS co-treated mice pretreated with TF-AS-injected.

B) interleukin-6 (IL-6) serum level (ng/ml) $24 \mathrm{~h}$ after veh., MCT/LPS with or without TF-SC, TF-SE or TF-AS. Bars indicate means \pm SEM where;

${ }^{a}$ Significantly different from veh. treated animals.

${ }^{\mathrm{b}}$ Significantly different from MPS/LPS co-treated animals.

${ }^{\mathrm{c}}$ Significantly different from MPS/LPS-TF co-treated animals. 


\section{A}
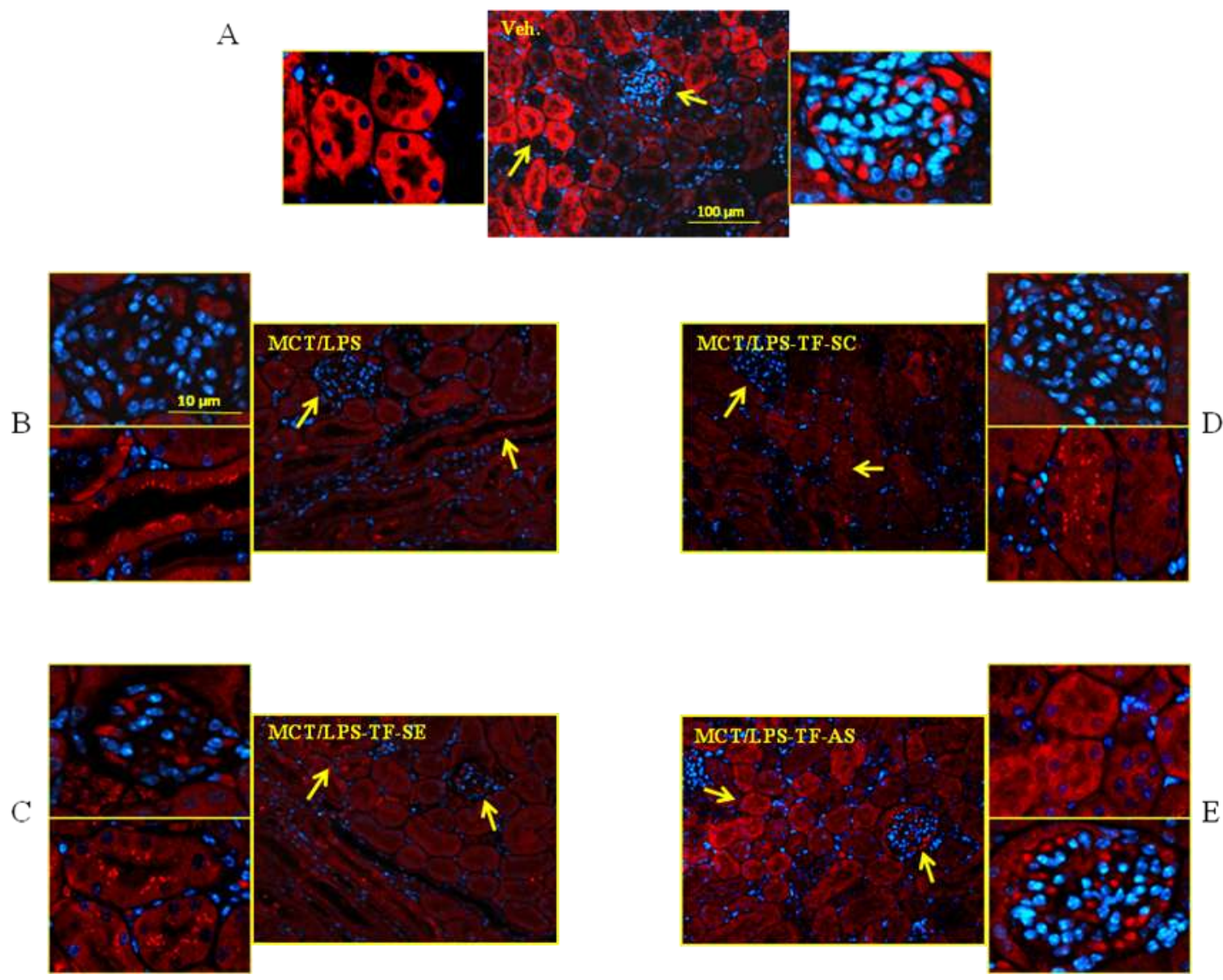

Figure 3: kidney sections of mice showing expression of RXR- $\alpha$ in normal, MCT/LPS, MCT/LPS-TF-SC, MCT/LPS-TF-SE and MCT/LPS-TF-AS treated mice. Mice treated with MCT/LPS (B), MCT/LPS-TF-SC (D) or MCT/LPS-TF-SE (C) cotreatment revealed a reduction of glomerular RXR- $\alpha$ expression compared to veh. Treated animals (A). Renal cortical tubules of high magnification power showing $(10 \mu \mathrm{m})$ translocation of RXR- $\alpha$ to the apical part of tubules compared to the basolateral expression in the veh. treated mice. No expression of RXR- $\alpha$ in the glomeruli after MCT/LPS co-treatment compared to the strong RXR- $\alpha$ expression in the veh. treated mice. MCT/LPS-TF-AS (E) co-treated mice showing normal glomerular and tubular expression of RXR- $\alpha$ compared to veh. treated mice $(\mathrm{A})$. 
A

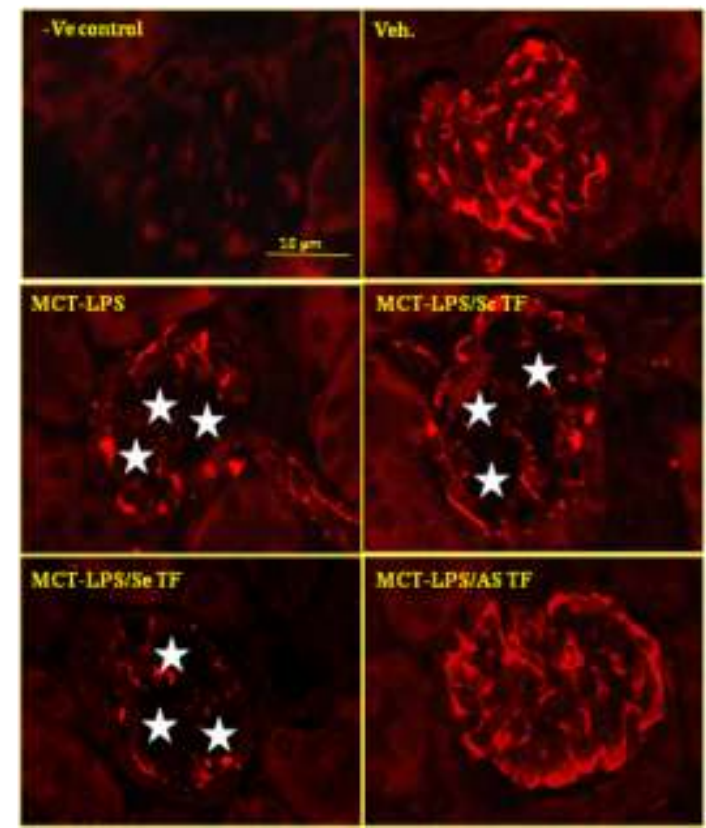

B

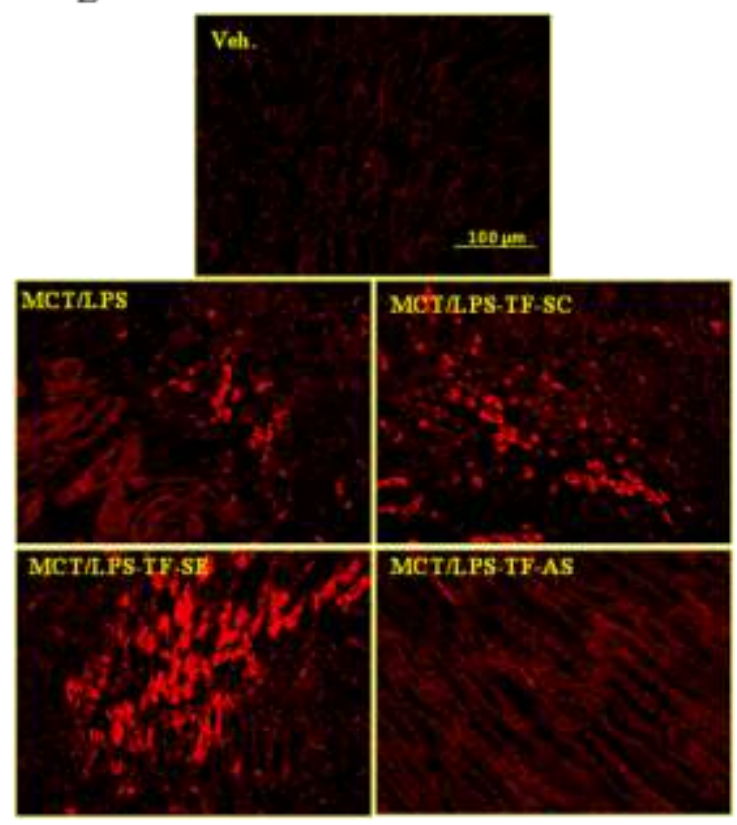

Figure 4: Expression of RAR- $\alpha$ protein in mice kidney tissues of normal, MCT/LPS, MCT/LPS-TF-SC, MCT/LPS-TF-SE and MCT/LPS-TF-AS treated mice. (A) Immunofluorescence staining of kidney sections $24 \mathrm{~h}$ after veh. treatment of mice, showing constitutive expression of RAR- $\alpha$ in the glomerular basement membrane and/or podocytes of the glomeruli. Mice subjected to MCT/LPS, MCT/LPS-TF-SC or MCT/LPS-TF-SE co-treatment revealed a reduction of glomerular RAR- $\alpha$ expression (stars) as well as glomerular atrophy. Mice cotreated with MCT/LPS-TF-AS showed normal RAR- $\alpha$ expression in glomeruli. (B) Renal medullary tubules show limited RAR- $\alpha$ expression in glomeruli of veh. treated mice. MCT/LPS, MCT/LPS-TF-SC or MCT/LPS-TF-SE cotreatment demonstrate appearance of $\mathrm{RXR}-\alpha$ in interstitial cortical cells (proliferative epithelial cells). Mice co-treated with MCT/LPS-TF-AS showed normal RXR- $\alpha$ expression in renal tubules compared to veh. treated ones.

\section{REFERENCE}

Abdel-Bakky, M. S., Hammad, M. A., Walker, L. A d Ashfaq, M. K. (2011): Tissue factor dependent liver injury causes release of retinoid receptors (RXR-alpha and RARalpha) as lipid droplets .Biochem Biophys Res Commun. $101-1 \leqslant 7$ ، $\{1$.

Abdel-Bakky, M. S., Hammad, M. A., Walkerit, L. A. \& Ashfaqi, M. K. (2010): Developing and characterizing a mouse model of hepatotoxicity using oral pyrrolizidine alkaloid (monocrotaline) administration, with potentiation of the liver injury by co-administration of LPS. Nat Prod Commun 5, 1457-1462.

Anderson, R. J., Ray, C. J. \& Hattler, B. G. (1998): Retinoic acid regulation of renal tubular epithelial and vascular smooth muscle cell function. J Am Soc Nephrol 9, 773781.

Argiles, A., Kraft, N. E., Hutchinson, P., Senes-Ferrari, S. \& Atkins, R. C. (1989): Retinoic acid affects the cell cycle and increases total protein content in epithelial cells. Kidney Int 36, 954-959. 
Belting, M., Dorrell, M. I., Sandgren, S., Aguilar, E., Ahamed, J., Dorfleutner, A., Carmeliet, P., Mueller, B. M., Friedlander, M. \& Ruf, W. (2004): Regulation of angiogenesis by tissue factor cytoplasmic domain signaling. Nat Med 10, 502509.

Bromberg, M. E., Sundaram, R., Homer, R. J., Garen, A. \& Konigsberg, W. H. (1999): Role of tissue factor in metastasis: functions of the cytoplasmic and extracellular domains of the molecule. Thromb Haemost 82, 88-92.

Camerer, E., Gjernes, E., Wiiger, M., Pringle, S. \& Prydz, H. (2000): Binding of factor VIIa to tissue factor on keratinocytes induces gene expression. J Biol Chem 275, 6580-6585.

Cirino, G., Cicala, C., Bucci, M., Sorrentino, L., Ambrosini, G., DeDominicis, G. \& Altieri, D. C. (1997): Factor $\mathrm{Xa}$ as an interface between coagulation and inflammation. Molecular mimicry of factor Xa association with effector cell protease receptor-1 induces acute inflammation in vivo. J Clin Invest 99, 24462451.

Cunningham, M. A., Romas, P., Hutchinson, P., Holdsworth, S. R. \& Tipping, P. G. (1999): Tissue factor and factor VIIa receptor/ligand interactions induce proinflammatory effects in macrophages. Blood 94, 3413-3420.

Cuzzocrea, S., De, S. G., Costantino, G., Ciliberto, G., Mazzon, E., De, S. A. \& Caputi, A. P. (1999).IL-6 knock-out mice exhibit resistance to splanchnic artery occlusion shock. J Leukoc Biol 66, 471-480.

Dolle, P., Ruberte, E., Leroy, P., Morriss-Kay, G. \& Chambon, P. (1990): Retinoic acid receptors and cellular retinoid binding proteins. I. A systematic study of their differential pattern of transcription during mouse organogenesis. Development 110, 1133-1151.

Drake, T. A., Cheng, J., Chang, A. \& Taylor, F. B., Jr. (1993): Expression of tissue factor, thrombomodulin, and E-selectin in baboons with lethal Escherichia coli sepsis. Am J Pathol 142, 1458-1470.

Edgington, T. S., Mackman, N., Fan, S. T. \& Ruf, W. (1992): Cellular immune and cytokine pathways resulting in tissue factor expression and relevance to septic shock. Nouv Rev Fr Hematol 34 Suppl, S15-S27.

Frank, R. D., Schabbauer, G., Holscher, T., Sato, Y., Tencati, M., Pawlinski, R. \& Mackman, N. (2005): The synthetic pentasaccharide fondaparinux reduces coagulation, inflammation and neutrophil accumulation in kidney ischemiareperfusion injury. J Thromb Haemost 3, 531-540.

Goodman, D. S. (1984): Vitamin A and retinoids in health and disease. $N$ Engl J Med 310, 1023-1031.

Hammad, M. A., Abdel-Bakky, M. S., Walker, L. A. \& Ashfaq, M. K. (2011): Oxidized low-density lipoprotein and tissue factor are involved in monocrotaline/lipopolysaccharide-induced hepatotoxicity. Arch Toxicol 85, 1079-1089.

Ishii, H., Horie, S., Kizaki, K. \& Kazama, M. (1992): Retinoic acid counteracts both the downregulation of thrombomodulin and the induction of tissue factor in cultured human endothelial cells exposed to tumor necrosis factor. Blood 80, 2556-2562. 
Johnson, K., Choi, Y., DeGroot, E., Samuels, I., Creasey, A. \& Aarden, L. (1998): Potential mechanisms for a proinflammatory vascular cytokine response to coagulation activation. J Immunol 160, 5130-5135.

Kavukcu, S., Turkmen, M. A. \& Soylu, A. (2001): Could the effective mechanisms of retinoids on nephrogenesis be also operative on the amelioration of injury in acquired renal lesions? Pediatr Nephrol 16, 689-690.

Kerr, R., Stirling, D. \& Ludlam, C. A. (2001): Interleukin 6 and haemostasis. Br J Haematol 115, 3-12.

Mach, F., Schonbeck, U., Bonnefoy, J. Y., Pober, J. S. \& Libby, P. (1997): Activation of monocyte/macrophage functions related to acute atheroma complication by ligation of CD40: induction of collagenase, stromelysin, and tissue factor. Circulation 96, 396-399.

Mangelsdorf, D. J. \& Evans, R. M. (1995): The RXR heterodimers and orphan receptors. Cell 83, 841-850.

Matsuyama, M., Yoshimura, R., Akioka, K., Okamoto, M., Ushigome, H., Kadotani, Y., Nakatani, T. \& Yoshimura, N. (2003): Tissue factor antisense oligonucleotides prevent renal ischemia-reperfusion injury. Transplantation 76, 786-791.

Mendelsohn, C., Batourina, E., Fung, S., Gilbert, T. \& Dodd, J. (1999): Stromal cells mediate retinoid-dependent functions essential for renal development. Development 126, 1139-1148.

Mezaki, Y., Yamaguchi, N., Yoshikawa, K., Miura, M., Imai, K., Itoh, H. \& Senoo, H. (2009): Insoluble, speckled cytosolic distribution of retinoic acid receptor alpha protein as a marker of hepatic stellate cell activation in vitro. $J$ Histochem Cytochem 57, 687-699.

Moreno-Manzano, V., Mampaso, F., Sepulveda-Munoz, J. C., Alique, M., Chen, S., Ziyadeh, F. N., Iglesias-de la Cruz MC, Rodriguez, J., Nieto, E., Orellana, J. M., Reyes, P., Arribas, I., Xu, Q., Kitamura, M. \& Lucio Cazana, F. J. (2003): Retinoids as a potential treatment for experimental puromycin-induced nephrosis. Br J Pharmacol 139, 823-831.

Nagpal, S. \& Chandraratna, R. A. (2000): Recent developments in receptor-selective retinoids. Curr Pharm Des 6, 919-931.

Ohata, M., Lin, M., Satre, M. \& Tsukamoto, H. (1997): Diminished retinoic acid signaling in hepatic stellate cells in cholestatic liver fibrosis. Am J Physiol 272, G589G596.

Poulsen, L. K., Jacobsen, N., Sorensen, B. B., Bergenhem, N. C., Kelly, J. D., Foster, D. C., Thastrup, O., Ezban, M. \& Petersen, L. C. (1998): Signal transduction via the mitogen-activated protein kinase pathway induced by binding of coagulation factor VIIa to tissue factor. J Biol Chem 273, 6228-6232.

Rothberger, H., Barringer, M. \& Meredith, J. (1984): Increased tissue factor activity of monocytes/macrophages isolated from canine renal allografts. Blood 63, 623628.

Rottingen, J. A., Enden, T., Camerer, E., Iversen, J. G. \& Prydz, H. (1995): Binding of human factor VIIa to tissue factor induces cytosolic Ca2+ signals in J82 cells, transfected COS-1 cells, Madin-Darby canine kidney cells and in human endothelial cells induced to synthesize tissue factor. $J$ Biol Chem 270, 46504660. 
Shapiro, P. S., Evans, J. N., Davis, R. J. \& Posada, J. A. (1996): The seventransmembrane-spanning receptors for endothelin and thrombin cause proliferation of airway smooth muscle cells and activation of the extracellular regulated kinase and c-Jun NH2-terminal kinase groups of mitogen-activated protein kinases. J Biol Chem 271, 5750-5754.

Shin, H., Kitajima, I., Nakajima, T., Shao, Q., Tokioka, T., Takasaki, I., Hanyu, N., Kubo, T. \& Maruyama, I. (1999): Thrombin receptor mediated signals induce expressions of interleukin 6 and granulocyte colony stimulating factor via NFkappa B activation in synovial fibroblasts. Ann Rheum Dis 58, 55-60.

Sorensen, B. B., Freskgard, P. O., Nielsen, L. S., Rao, L. V., Ezban, M. \& Petersen, L. C. (1999): Factor VIIa-induced p44/42 mitogen-activated protein kinase activation requires the proteolytic activity of factor VIIa and is independent of the tissue factor cytoplasmic domain. J Biol Chem 274, 21349-21354.

Stankova, J., Rola-Pleszczynski, M. \& D'Orleans-Juste, P. (1995): Endothelin 1 and thrombin synergistically stimulate IL-6 mRNA expression and protein production in human umbilical vein endothelial cells. J Cardiovasc Pharmacol 26 Suppl 3, S505-S507.

Sugawara, A., Sanno, N., Takahashi, N., Osamura, R. Y. \& Abe, K. (1997): Retinoid X receptors in the kidney: their protein expression and functional significance. Endocrinology 138, 3175-3180.

Susztak, K., Raff, A. C., Schiffer, M. \& Bottinger, E. P. (2006): Glucose-induced reactive oxygen species cause apoptosis of podocytes and podocyte depletion at the onset of diabetic nephropathy. Diabetes 55, 225-233.

Takada, M., Nadeau, K. C., Shaw, G. D., Marquette, K. A. \& Tilney, N. L. (1997): The cytokine-adhesion molecule cascade in ischemia/reperfusion injury of the rat kidney. Inhibition by a soluble P-selectin ligand. J Clin Invest 99, 2682-2690.

Tenno, T., Botling, J., Oberg, F., Jossan, S., Nilsson, K. \& Siegbahn, A. (2000): The role of RAR and RXR activation in retinoid-induced tissue factor suppression. Leukemia 14, 1105-1111.

Ushigome, H., Sano, H., Okamoto, M., Kadotani, Y., Nakamura, K., Akioka, K., Yoshimura, R., Ohmori, Y. \& Yoshimura, N. (2002): The role of tissue factor in renal ischemic reperfusion injury of the rat. J Surg Res 102, 102-109.

Yang, T., Michele, D. E., Park, J., Smart, A. M., Lin, Z., Brosius, F. C., III, Schnermann, J. B. \& Briggs, J. P. (1999): Expression of peroxisomal proliferator-activated receptors and retinoid X receptors in the kidney. Am J Physiol 277, F966-F973.

Yee, S. B., Harkema, J. R., Ganey, P. E. \& Roth, R. A. (2003): The coagulation system contributes to synergistic liver injury from exposure to monocrotaline and bacterial lipopolysaccharide. Toxicol Sci 74, 457-469. 
تسمم الكلي المحثث بالمونوكروتالين/ليبوبوليساكاريد: نظره علي الأعتماد المتبادل بين مستقبلات RAR- $\alpha$,RXR- $\alpha$

\section{محمد صادق عبد الباقى}

قسم علم الأدوية والسموم - كلية الصيدلة (بنين بالقاهرة) - جامعة الأزهر

لامستقبلات ال RXR ,RAR وظيفه هامه في حياة الخلايا ونموها وتحورها وموتها عند ارتباطهما سويا.

ونظرا لأهمية هذه الوظائف تظل هذه المستقبلات هدفا لبعض الأدويه المستخدمه لعلاج الكثير من الأمراض منها

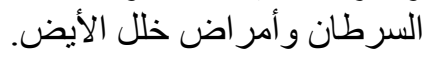

أما فى الكلى فإن المعلومات عن تواجد RXR- $\alpha$, RAR- ورظيفتهما قليلة للغاية غير ان معظم مستقبلات

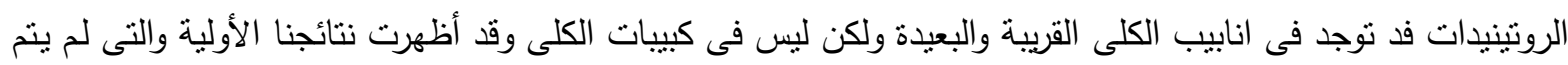

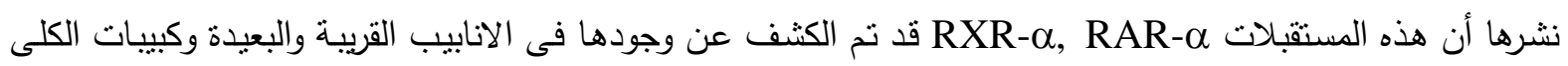

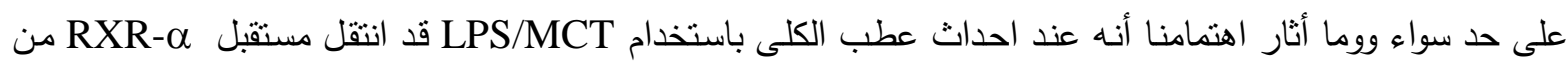

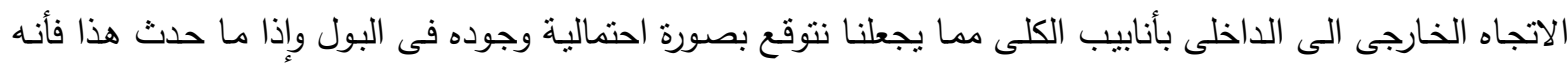

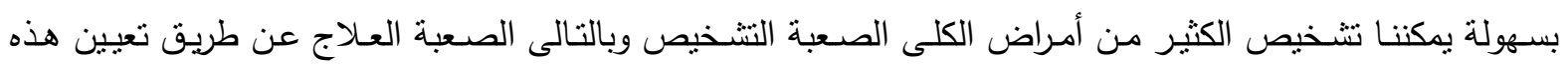

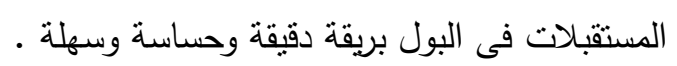

وخلاصة القول استخدام نيوكليوتيدات TF قد اوققت هذا الانتقال المرضى ولهذا فإن هذه الدراسة تهدف الى لى

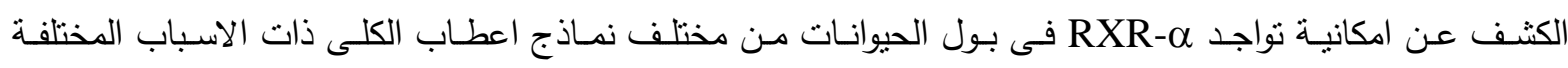

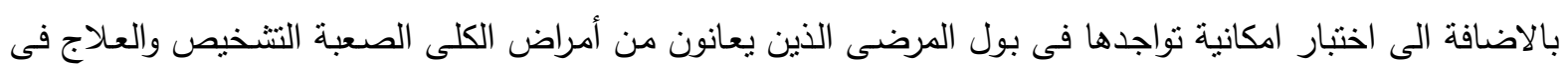

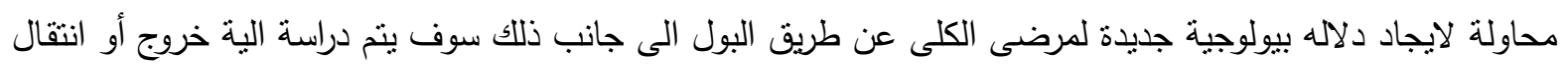

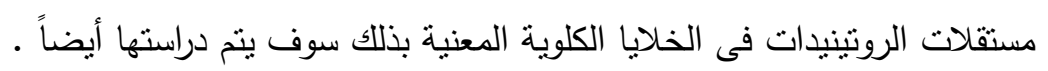

